\title{
Effect of soft story on structural response of high rise buildings.
}

\begin{abstract}
Severe structural damage suffered by several modern buildings during recent earthquakes illustrates the importance of avoiding sudden changes in lateral stiffness and strength. Recent earthquakes that occurred have shown that a large number of existing reinforced concrete buildings are vulnerable to damage or even collapse during a strong earthquake. While damage and collapse due to soft story are most often observed in buildings, they can also be developed in other types of structures. The lower level containing the concrete columns behaved as a soft story in that the columns were unable to provide adequate shear resistance during the earthquake. Usually the most economical way of retrofitting such as a building is by adding proper bracing to soft stories. So, in this paper occurring of soft at the lower level of high rise buildings subjected to earthquake has been studied. Also has been tired to investigate on adding of bracing in various arrangements to structure in order to reduce soft story effect on seismic response of building. It is lead to assess the vulnerability level of existing multi-storied buildings so that they can be retrofitted to possess the minimum requirements. This will help in minimizing the impending damages and catastrophes.
\end{abstract}

Keyword: Concrete column; Existing reinforced concrete; High rise building; In-buildings; Lateral stiffness 